\title{
FAKTOR YANG BERHUBUNGAN DENGAN KEJADIAN INFERTILITAS PADA WANITA USIA SUBUR DI RSU SAWERIGADING PALOPO TAHUN 2016
}

\author{
Factors Associated With Infertility In Genesis Women of fertile age \\ in RSU Sawerigading Palopo, 2016 \\ Yusriani Muslimin, ${ }^{1}$ Wahyuni Arif, ${ }^{2}$ Resty Ryadinency ${ }^{3}$ \\ ${ }^{1}$ Prodi DIV STIKES Mega Buana Palopo (E-mail : yusriani@yahoo.com) \\ ${ }^{2}$ Dosen STIKES Mega Buana Palopo (E-mail : karamedinakara@gmal.com) \\ ${ }^{3}$ Dosen STIKES Mega Buana Palopo (E-mail : resty.gizi@gmail.com)
}

\begin{abstract}
Infertility is the inability of a couple to produce a pregnancy after 1 year carry out regular sexual intercourse and not using contraception. To determine the factors associated with the incidence of infertility in women of childbearing age in the General Hospital Sawerigading Palopo 2016. This study was an analytical survey with cross sectional study design. The population in this study were all women of childbearing age who came medical check up in Palopo Sawerigading Hospital from March to June, 2016 as many as 240 people. 70 subjects were selected by purposive sampling technique. The data was processed by the statistical program (SPSS) version 20 for windows. Data were analyzed by Chi-Square test using Yates Correction and Pearson Chi-Square test. There is relationship between the work with the incidence of infertility in women of childbearing age $p=$ 0.047 ( $p$ <0.05). There is relationship between knowledge and the incidence of infertility in women of childbearing age $p=0.018$ ( $p$ <0.05). There is relationship between nutritional status and the incidence of infertility in women of childbearing age $p=0.011(p<0.05)$. No relationship of age and nutritional status and the incidence of infertility in women of childbearing age in the RSU Sawerigading Palopo 2016.
\end{abstract}

Keywords: Infertility, age, nutritional status

\section{PENDAHULUAN}

Hampir setiap pasang di dunia mengiginkan seorang anak, namun tidak setiap perkawinan dianugrahi keturunan. Salah satu gangguan reproduksi yang terjadi pada usia subur adalah infertilitas. Di mana Infertilitas merupakan masalah yang di hadapi pasangan suami istri yang telah menikah selama minimal satu tahun, melakukan hubungan senggama teratur tanpa menggunakan kontrasepsi tetapi belum berhasil memperoleh kehamilan. ${ }^{1.2}$

Infertilitas pada wanita dibedakan atas infertilitas primer dan infertilitas sekunder. Dikatakan infertilitas primer jika seorang wanita yang telah berkeluarga belum pernah mengalami kehamilan meskipun hubungan seksual dilakukan secara teratur tanpa perlindungan kontrasepsi untuk selang waktu paling kurang 12 bulan. $^{3}$

Sedangkan dikatakan infertilitas sekunder jika seorang wanita yang telah berkeluarga sudah pernah mengalami kehamilan akan tetapi tidak berhasil hamil lagi setelah melakukan hubugan seksual secara teratur tanpa menggunakan alat kontrasepsi selama 1 tahun. ${ }^{4}$

Penyebab terjadinya infertilitas dibagi menjadi dua faktor yaitu faktor dari wanita dan faktor pria, faktor dari wanita meliputi 
faktor tuba dan pelvik (35\%) Sumbatan atau kerusakan tuba akibat perlekatan atau akibat endometriosis, faktor ovulasi $15 \%$ ovulasi jarang atau tidak ada ovulasi, polip endometrium dan kelainan bentuk uterus (5\%). Faktor dari laki - laki (35\%) abnormalitas jumlah, motilitas dan morfologi sperma. $^{5}$

World Health Organization (WHO) mengatakan bahwa jumlah pasangan infertil sebanyak 36\% diakibatkan adanya kelainan pada pria, sedangkan $64 \%$ berada pada wanita. Hal ini di alami oleh $17 \%$ pasangan yang sudah menikah lebih dari 2 tahun yang belum mengalami tanda - tanda kehamilan bahkan sama sekali belum hamil, WHO juga memperkirakan sekitar $50-80$ juta pasutri (1- 7 pasang memiliki masalah infertil) dan setiap tahunnya muncul sekitar 2 juta pasangan infertil. ${ }^{6}$

Status gizi juga dapat menyebabkan terjadinya infertilitas dimana jika seorang wanita memiliki berat badan yang berlebih (over weight) atau mengalami kegemukan (obesitas), atau dengan istilah lain memiliki tubuh $10 \%-15 \%$ dari lemak tubuh normal, maka wanita tersebut akan menderita gangguan pertumbuhan folikel di ovarium yang terkait dengan sebuah sindrom yaitu Sindrom Ovarium Poli Kistik (SPOK). Sindrom ini juga terkait erat dengan resistensi insulin dan diabetes mellitus. Disamping berat badan yang berlebih maka berat badan yang sangat rendah juga dapat mengganggu fungsi fertilisasi seorang wanita. $^{7}$

Menurut penelitian yang dilakukan di Wilayah Kecamatan Way, Seputih Kabupaten Lampung Tengah Tahun 2014 tentang faktor yang berhubungan dengan kejadian infertilitas di dapatkan hasil bahwa nilai $p$ value 0,018 sehingga ada hubungan status gizi dengan kejadian infertilitas. ${ }^{8}$

Berdasarkan data yang diperoleh dari Rumah Sakit Umum Sawerigading Palopo tahun 2013 angka kejadian infertilitas sebanyak 73 kasus pada tahun 2014 angka kejadian infertil sebanyak 72 kasus dan pada 2015 sebanyak 59 kasus.
Tujuan penelitian ini untuk mengetahui faktor yang berhubungan dengan kejadian infertilitas pada wanita usia subur di rumah sakit umum sawerigading palopo tahun 2016.

\section{METODE PENELITIAN}

Jenis penelitian yang digunakan adalah penelitian survey analitik dengan pendekatan cross sectional study. ${ }^{9}$

Penelitian ini dilaksanakan di RSU Sawerigading Palopo yang bertempat jalan dr. Ratulangi Rampoang km.7. Penelitian di laksanakan pada bulan April - Juli tahun 2016.

Populasi dalam penelitian ini adalah semua wanita usia subur yang datang memeriksakan diri pada bulan April - Juli di ruang poli KIA Rumah Sakit Umum Swerigading Palopo tahun 2016 berjumlah 240 orang.

Sampel dalam penelitian ini sebanyak 70 sampel, Teknik Pengambilan sampel yang digunakan dalam penelitian ini adalah accidental sampling. ${ }^{10}$

Data primer diperoleh melalui wawancara langsung kepada responden serta lembar observasi.

Analisa data dilakukan dengan analisis kuantitatif, yang terdiri dari analisis univariat (disajikan dalam bentuk distribusi frekuensi), analisis bivariat dengan menggunakan uji Chi-Square dengan menggunakan program SPSS versi 20.0 dengan taraf kesalahan $(\alpha=0,05)$.

\section{HASIL}

Tabel 1 menunjukkan bahwa dari 70 responden yang diteliti, sebanyak 33 responden yang tidak mengalami infertilitas dan sebanyak 37 responden yang mengalami infertilitas.

Tabel 2 menunjukkan bahwa dari hasil penelitian dengan 70 responden terdapat 34 responden $(48,6 \%)$ yang memiliki usia tidak beresiko ( $<35$ tahun) di mana 22 responden $(31,4 \%)$ yang tidak mengalami infertilitas dan 12 responden $(17,1 \%)$ yang mengalami infertilitas serta terdapat 36 responden yang memiliki usia beresiko ( $>35$ tahun) di mana 11 responden $(15,7 \%)$ yang tidak mengalami 
infertilitas dan 25 responden $(35,7 \%)$ yang mengalami infertilitas. Dari hasil analisis dengan menggunakan uji Yates Correction menggunakan spss 20 maka diperoleh nilai $p$ $=0,009(p<0,05)$ sehingga Ha diterima dan Ho ditolak yang artinya terdapat hubungan yang signifikan antara usia dengan kejadian infertilitas.

Tabel 3 menunjukkan bahwa dari hasil penelitian dengan 70 responden, terdapat 19 responden $(27,1 \%)$ yang memiliki status gizi kurang di mana terdapat 8 responden $(11,4 \%)$ yang tidak mengalami inferilitas dan 11 responden $(15,7 \%)$ yang mengalami infertilitas, serta terdapat 23 responden
$(32,9 \%)$ yang memiliki status gizi lebih di mana terdapat 6 responden $(8,6 \%)$ yang tidak mengalami infertilitas dan 17 responden $(24,3 \%)$ yang mengalami infertilitas serta 28 responden $(40,0 \%)$ yang memiliki status gizi normal di mana terdapat 19 responden $(27,1 \%)$ yang tidak mengalami infertilitas dan terdapat 9 responden $(12,9 \%)$ yang mengalami infertilitas. Dari hasil analisis menggunakan uji Pearson Chi-Square maka diperoleh nilai $p=0,011(p<0,05)$ sehingga Ha diterima dan Ho di tolak yang artinya terdapat hubungan yang signifikan antara status gizi dengan kejadian infertilitas.

Tabel 1

Distribusi frekuensi responden berdasarkan usia dan status gizi di RSU Sawerigading Palopo Tahun 2016

\begin{tabular}{ccc}
\hline Variabel & \multicolumn{2}{c}{ Jumlah } \\
\cline { 2 - 3 } Infertilitas & n & Persen (\%) \\
Tidak & 33 & 47,1 \\
Ya & 37 & 52,9 \\
Usia & & \\
Tidak beresiko & 34 & 48,6 \\
Beresiko & 36 & 51,4 \\
Status gizi & & \\
Kurang & 19 & 27,1 \\
Lebih & 23 & 32,9 \\
Normal & 28 & 40,0 \\
\hline
\end{tabular}


Tabel 2

Distribusi analisis hubungan usia dengan kejadian infetilitas pada wanita usia subur di RSU Sawerigading Palopo

Tahun 2016

\begin{tabular}{ccccccccc}
\hline \multirow{2}{*}{ Usia } & \multicolumn{4}{c}{ Infertilitas } & \multicolumn{2}{c}{ Total } & \multirow{2}{*}{ p-value } \\
\cline { 2 - 6 } & \multicolumn{2}{c}{ Tidak } & \multicolumn{2}{c}{ Ya } & & \\
\cline { 2 - 6 } & $\mathbf{n}$ & $\mathbf{\%}$ & $\mathbf{n}$ & $\mathbf{\%}$ & $\mathbf{n}$ & $\mathbf{\%}$ & \\
\hline Tidak beresiko & 22 & 31,4 & 12 & 17,1 & 34 & 48,6 & \\
\hline Beresiko & 11 & 15,7 & 25 & 35,7 & 36 & 51,4 & 0,009 \\
\hline Total & $\mathbf{3 3}$ & $\mathbf{4 7 , 1}$ & $\mathbf{3 7}$ & $\mathbf{5 2 , 9}$ & $\mathbf{7 0}$ & $\mathbf{1 0 0}$ & \\
\hline
\end{tabular}

Sumber: Yates Correction, 2016

Tabel 3

Distribusi analisis hubungan status gizi dengan kejadian infertilitas pada wanita usia subur di RSU Sawerigading Palopo

Tahun 2016

\begin{tabular}{cccccccc}
\hline & \multicolumn{4}{c}{ Infertilitas } & \multicolumn{2}{c}{ Total } & \multirow{2}{*}{ p-value } \\
\cline { 2 - 6 } Status Gizi & \multicolumn{2}{c}{ Tidak } & \multicolumn{2}{c}{ Ya } & & \\
\cline { 2 - 6 } & $\mathbf{n}$ & $\mathbf{\%}$ & $\mathbf{n}$ & $\mathbf{\%}$ & $\mathbf{n}$ & $\mathbf{\%}$ & \\
\hline Kurang & 8 & 11,4 & 11 & 15,7 & 19 & 27,1 & \\
\hline Lebih & 6 & 8,6 & 17 & 24,3 & 23 & 32,9 & \multirow{2}{*}{0,011} \\
\hline Normal & 19 & 27,1 & 9 & 12,9 & 28 & 40,0 & \\
\hline Total & $\mathbf{3 3}$ & $\mathbf{4 7 , 1}$ & $\mathbf{3 7}$ & $\mathbf{5 2 , 9}$ & $\mathbf{7 0}$ & $\mathbf{1 0 0}$ &
\end{tabular}

Sumber: Pearson Chi-Square, 2016

\section{PEMBAHASAN}

Hubungan usia dengan kejadian
infertilitas

Berdasarkan hasil analisis menggunakan uji Yates Correction menggunakan spss 20 maka diperoleh nilai $p=0,009(p<0,05)$ sehingga Ha diterima dan Ho ditolak yang artinya terdapat hubungan yang signifikan antara usia dengan kejadian infertilitas.

Penelitian yang dilakukan di Wilayah Kecematan Way Seputih Kabupaten Lampung Tengah 2014, tentang analisis faktor kejadian infertilitas, bahwa ada hubungan usia dengan kejadian infertilitas.
Hasil penelitian menunjukkan dari 72 responden yang mempunyai umur beresiko (>35 tahun) dan 21 responden lainnya mempunyai umur yang tidak beresiko. ${ }^{7}$

Hal ini didukung dengan penelitian yang dilakukan di Klinik Fertilisasi Endokrinologi Reproduksi tahun 2014, tentang faktor faktor yang mempengaruhi infertilitas pada wanita, dimana penelitian menunjukkan bahwa tampak dari 49 wanita dengan infetilitas primer, sebagia besar yakni 35 orang $(71,4 \%)$ merupakan wanita infertil Tahun 2014 tentang yang berada pada rentang umur 25 - 35 tahun sedangkan sisanya yaitu 11 orang $(22,5 \%)$ berada pada 
umur diatas 35 tahun. Hanya 3 orang $(6,1 \%)$ wanita infertil dengan infetilitas primer berumur di bawah 25 tahun. Dari 13 orang wanita dengan infertilitas sekunder, sebagian besar diantaranya yaitu 9 orang $(69,2 \%)$ merupakan wanita yang berada pada rentang umur 25 - 35 tahun sisanya empat orang $(30,8 \%)$ wanita dengan infertil sekunder berada pada kelompok umur diatas 35 tahun, tidak didapatkan wanita dengan infertilitas sekunder yang berumur kurang dari 25 tahun. ${ }^{11}$

Banyaknya ibu yang mengalami infertilitas dengan usia >35 tahun dikarenakan sangat jarang mengadakan penyuluhan tentang kesehatan reproduksi khususnya masalah kesuburan yang diakibatkan oleh banyak faktor diantaranya adalah umur yang beresiko. Hal ini sejalan dengan teori yang mengatakan bahwa ketika seorang wanita semakin berumur, maka semakin kecil pula kemungkinan wanita tersebut untuk hamil. Kejadian infertilitas berbanding lurus dengan pertambahan usia wanita. Wanita yang sudah berumur akan memliki kualitas oosit yang tidak baik akibat adanya kelainan kromoson pada oosit tersebut. $^{6}$

\section{Hubungan status gizi dengan kejadian infertilitas}

Berdasarkan hasil analisis menggunakan uji Pearson Chi-Square maka diperoleh nilai $p=0,011(p<0,05)$ sehingga Ha diterima dan Ho di tolak yang artinya terdapat hubungan yang signifikan antara status gizi dengan kejadian infertilitas.

Hasil penelitian tersebut didukung oleh penelitian yang dilakukan di Wilayah Kecamatan Way, Seputih Kabupaten Lampung Tengah Tahun 2014 tentang hubungan status gizi dengan infertilitas. Hasil penelitian menunjukkan bahwa status gizi tidak normal terjadi pada 56 responden dengan perhitungan $\mathrm{BMI}<18,5$ dan di $>$ 25,0 , responden dengan infertilitas primer yang mempunyai status gizi tidak normal sebanyak 27 responden $(48,2 \%)$, dan pada infertilitas sekunder yang mengalami status gizi tidak normal sebanyak 29 responden $(51,8 \%)$. Uraian di atas membuktikan bahwa status gizi secara statistik berhubungan dengan infertilitas dengan $p$ value $0,018 .{ }^{7}$

Oleh karena itu agar tidak terjadi infertilitas diharapkan kepada ibu untuk mengatur pola makan dan makan makanan yang bergizi. Hal ini sejalan dengan teori Status gizi juga dapat menyebabkan terjadinya infertilitas dimana jika seorang wanita memiliki berat badan yang berlebih (over weight) atau mengalami kegemukan (obesitas), atau dengan istilah lain memiliki tubuh $10 \%-15 \%$ dari lemak tubuh normal, maka wanita tersebut akan menderita gangguan pertumbuhan folikel di ovarium yang terkait dengan sebuah sindrom yaitu Sindrom Ovarium Poli Kistik (SPOK). Sindrom ini juga terkait erat dengan resistensi insulin dan diabetes mellitus. Di samping berat badan yang berlebih maka berat badan yang sangat rendah juga dapat mengganggu fungsi fertilisasi seorang wanita. $^{6}$

\section{KESIMPULAN}

Ada hubungan usia ibu dengan kejadian infertilitas di Rumah Sakit Umum Sawerigading Palopo tahun 2016 dengan nilai $p=0,009(p<0,05)$. Ada hubungan Status Gizi dengan kejadian infertilitas di Rumah Sakit Umum Sawerigading Palopo tahun 2016 dengan nilai $p=0,011(p<0,05)$.

petugas medis atau para medik seperti dokter kandungan dan bidan, untuk meningkatkan frekuensi peenyuluhan pemberian informasi kesehatan kepada ibu terutama mengenai pentingnya mengetahui faktor -faktor yang dapat menyebabkan terjadinya infertilitas pada ibu.

\section{REFERENSI}

1. Prawirohardjo S. Ilmu Kebidanan. Jakarta: Yayasan Bina Pustaka; 2011: 120-121. 
2. Manuaba IAC, Manuaba IBGF, Manuaba IBG. Ilmu Kebidanan, Penyakit Kandungan dan KB. Jakarta: EGC; 2012: 653.

3. Prawirohardjo S. Ilmu Kandungan. Yogyakarta: PT Bina Pustaka; 2010: 425.

4. Manuaba IAC, Manuaba IBGF, Manuaba IBG. Memahami Kesehatan Reproduksi Wanita. Jakarta: EGC; 2009: 255-256.

5. Widyastuti Y, Rahmawati A, Purnamaningrum YE. Kesehatan Reproduksi. Yogyakarta: Fitramaya; 2012: 29-30.

6. WHO. Angka Kejadian Infertilitas. Genova: Indonesia; 2012.

7. Sibagariang EE. Gizi Dalam Kesehatan Reproduksi. Jakarta: TIM; 2010: 111.

8. Karsiyah. Analisis Faktor yang Berhubungan dengan Infertilitas. Jurnal Kebidanan Adila Bandar Lampung, 2014; 12 (2): 5-6.

9. Nasir A, Muhith A, Ideputri ME. Metodologi Penelitian Kesehatan. Yogyakarta: nuha medika; 2013: 140.

10. Sugiona. Metode Penelitian Kuantitatif, Kualitatif dan R \& D. Bandung: Alfabeta; 2012: 85.

11. Oktarina A. Faktor - faktor yang Mempengaruhi Infertilitas Pada Wanita di Kilinik Fertilitas Endokrinologi Reproduksi. Jurnal Kebidanan, 2014; 2 (5): 3-4. 
